\title{
MicroRNA-361-3p suppresses tumor cell proliferation and metastasis by directly targeting $\mathrm{SH} 2 \mathrm{~B} 1$ in NSCLC
}

\author{
Wei Chen 1 , Jun Wang ${ }^{2}$, Sulai Liư ${ }^{3}$, Shaoqiang Wang', Yuanda Cheng ${ }^{1}$, Wolong Zhou', Chaojun Duan² \\ and Chunfang Zhang ${ }^{1 *}$
}

\begin{abstract}
Background: Lung cancer is the most common malignancies worldwide. However, the detailed molecular mechanisms underlying lung cancer progression are still not completely clear. MicroRNAs are small noncoding RNAs which occupy a crucial role of cancer metastasis. Accumulating evidence suggests that miR-361 plays important roles in human carcinogenesis. However, its precise biological role remains largely elusive, especially in lung cancer. This study examined the role of miR-361-3p in non-small cell lung cancer (NSCLC).

Methods: Real-time quantitative PCR (qRT-PCR) was used to analyze the expression of miR-361-3p in NSCLC tissue and in compared adjacent non-cancerous tissues. The effect of miR-361-3p on proliferation was evaluated by CCK8 and colony formation assays. The effect of miR-361-3p on migration and invasion was evaluated by transwell assays. Western blotting and immunohistochemical staining were applied to analyze the expression of target proteins and downstream molecule, and the luciferase reporter assay to assess the target genes of miR-361-3p in non-small cell lung cancer cells.

Results: miR-361-3p was significantly decreased in NSCLC tissue and cell lines, and its expression levels were highly correlated with lymph node metastasis $(P<0.01)$ and TNM stages $(P<0.05)$. Down-regulation of miR-361-3p promoted cell growth, proliferation, colony formation, invasion and migration in vitro, and promoted proliferation and metastasis in vivo $(P<0.01)$; whereas up-regulation of miR-361-3p had the contrary effects. The luciferase reporter assay showed that SH2B1 was a direct target gene of miR-361-3p. Enforced expression of miR-361-3p inhibited the expression of $\mathrm{SH} 2 \mathrm{~B} 1$ significantly and the restoration of $\mathrm{SH} 2 \mathrm{~B} 1$ expression reversed the inhibitory effects of miR-361-3p on NSCLC cell proliferation and metastasis.

Conclusions: miR-361-3p functions as a novel tumor suppressor in NSCLC and the anti-oncogenic activity may involve its inhibition of the target gene SH2B1. These findings suggest the possibility for miR-361-3p as a therapeutic target in NSCLC.
\end{abstract}

Keywords: miR-361-3p, Progression, NSCLC, SH2B1

\section{Background}

Lung cancer is the highest mortality malignant tumor in China and African Americans [1,2]. Non-small-cell lung cancer (NSCLC) accounts for about $80 \%$ of all lung cancer cases, including adenocarcinoma and squamous cell carcinoma. Due to lacking obvious symptoms for early

\footnotetext{
* Correspondence: zcf6636169@sina.com

'Department of Thoracic Surgery, Xiangya Hospital, Central South University, Xiangya Road 87th, Changsha 410008, Hunan, PR China

Full list of author information is available at the end of the article
}

diagnosis and highly malignant potential, the 5-year survival rate of NSCLC is still less than $15 \%$ [3]. Recent years, low-dose computed tomography (LDCT) screening is employed in high risk patients to detect early stage disease, while it was shown to reduce mortality its usefulness is limited by high false-positive rates $[4,5]$. These issues highlight the urgent need for accurate that can detect early lung cancer with high sensitivity and specificity. 
MicroRNAs (miRNAs) are highly conserved small non-coding regulatory RNAs with sizes of 17-25 nucleotides, which are able to regulate gene expression via binding to the 3'-untranslated regions (UTR) of target mRNAs [6], and was first reported by Ambros and Ruvkun in 1993 [7, 8]. Ample evidence shows that altered miRNA expression result in the initiation, promotion, and progression of NSCLC, such as miRNA-21 [9], miRNA-205 [10], miR-1254 and miR-574-5p [11]. Although the importance of miRNAs has attracted much attention in recent years, the pathological relevance and significance of the majority of miRNAs in NSCLC remain unclear. Thus, understanding of the underlying molecular mechanisms of miRNA dysregulation in malignant tumors is critical to intervention of lung cancer.

Recent studies have shown that miR-361 expression was alternant in several cancer types, for example squamous cell carcinoma [12], cervical cancer [13], prostate cancer [14], colorectal and gastric cancer [15], hepatocellular carcinoma [16]. Such researches imply that miR361 may play important roles in cancer depending on the tumor type. In this study, we aimed to evaluate the possible roles and related target genes of miR-361-3p in tumorigenesis of NSCLC. We found that the expression level of miR-361-3p in NSCLC was significantly lower in NSCLC tissues than in the corresponding normal lung tissues, and inversely associated with advanced stage and lymph node metastasis of NSCLC. Furthermore, enforced miR-361-3p expression inhibited lung cancer cell growth, proliferation, clone formation, migration and invasion in vitro, and tumorigenicity and intrapulmonary metastasis in vivo. In addition, The SH2B1 was identified as a functional target of miR-361-3p. Therefore, down-regulation of miR-361-3p suppresses lung cancer progression and metastasis through regulation of SH2B1.

\section{Results}

Expression of miR-361-3p is inversely associated with clinicopathologic characteristics and prognosis of NSCLC In previous research, we noticed that miR-361-3p was lowexpressed in NSCLC [17]. To confirm, we evaluated the expression of miR-361-3p in 91 pairs of frozen NSCLC tissues and the corresponding normal lung tissues which located $5 \mathrm{~cm}$ apart from tumor by quantitative reverse transcriptase PCR (qRT-PCR). For training cohort, miR-361-3p expression was downregulated in NSCLC tissues compared with the matching normal lung tissues, the median was $0.70 \mathrm{vs} .1$ (Fig. 1a). Furthermore, miR-361-3p expression was significantly inversely associated with metastasis and tumor nodes and Metastasis(TNM) stages of the patients (Table $1, P<0.05$ ). In addition, miR-361-3p expression was significantly lower in NSCLC tissue which displayed lymph node metastasis than did not (Fig. 1b) $(P<0.05)$, and decreased statistically with increasing stage of NSCLC $(P<0.05)$ (Fig.1c). Therefore, the low miR-361-3p expression was closely related to the progression and metastasis of NSCLC. We also evaluated miR-361-3p expression in six NSCLC cell lines (A549, HTB-182, PC-9, NCI-H1299, LTEP-A-2, SPC-A-1) and a normal human bronchial epithelial cell line (HBE). The relative expression levels for miR-361$3 p$ in these six NSCLC cell lines were 0.005, 0.091, $0.093,0.118,0.436$, and 0.475 , respectively, as compared with that of HBE cells, respectively (Fig. 1d). Remarkably, A549 a squamous cell carcinoma cell line, and HTB-182 an adenocarcinoma cell line, which expressed the lowest miR-361-3p level, consistent with the association of miR-361-3p with NSCLC metastasis as observed in NSCLC patient samples.

\section{MiR-361-3p inhibits NSCLC cell proliferation, migration and invasion in vitro}

To functionally characterize miR-361-3p in NSCLC, we restored the expression of miR-361-3p by ectopic expression of this miRNA in the lowest expression NSCLC cell line (A549 and HTB-182) and downregulated miR361-3p in the highest expression NSCLC cell line (SPCA-1). To this end miR-361-3p stably overexpressed A549 miR-361-precursor and HTB-182 ${ }^{\text {miR-361-precursor cells }}$ and stably downregulated in SPCA- $1^{\text {anti-miR-361-3p }}$ cells were generated. The different levels of miR-361-3p expression were confirmed by real-time PCR (Fig. 1e).

Cell Counting Kit-8(CCK8) and colony formation assays performed to assess the role of miR-361-3p in NSCLC cell proliferation. The result showed that compared with the control group, with forced expression of miR-361-3p impaired in both A549 miR-361-precursor and HTB-182 miR-361-precursor cells, Cell Counting Kit-8(CCK8) (Fig. 2a) and colony formation assays (Fig. 2b) showed that cell proliferation were significantly repressed. On the contrary, the cell proliferation of SPCA-1 ${ }^{\text {anti-miR-361-3p }}$ cells was significantly enhanced. Similarly, wound healing assay showed wound closure of miR-361-3p impaired in both A549 miR-361-precursor and HTB-182 miR-361-precursor were significantly slow. Furthermore, transwell assays showed the migratory and invasive abilities was significantly decreased (Fig. 3a, b), whereas reduced miR-361-3p expression inSPC-A- $1^{\text {anti-miR-361-3p }}$ cells resulted in the opposite result (Fig. 3c). These results indicated that miR-361-3p inhibits NSCLC cell proliferation and metastasis in vitro.

\section{Overexpression of miR-361-3p inhibits tumor growth and metastasis of NSCLC cells in vivo}

Given that miR-361-3p impaired the proliferation, migration and invasion of NSCLC cells in vitro, we examined whether miR-361-3p could affect tumorigenicity 


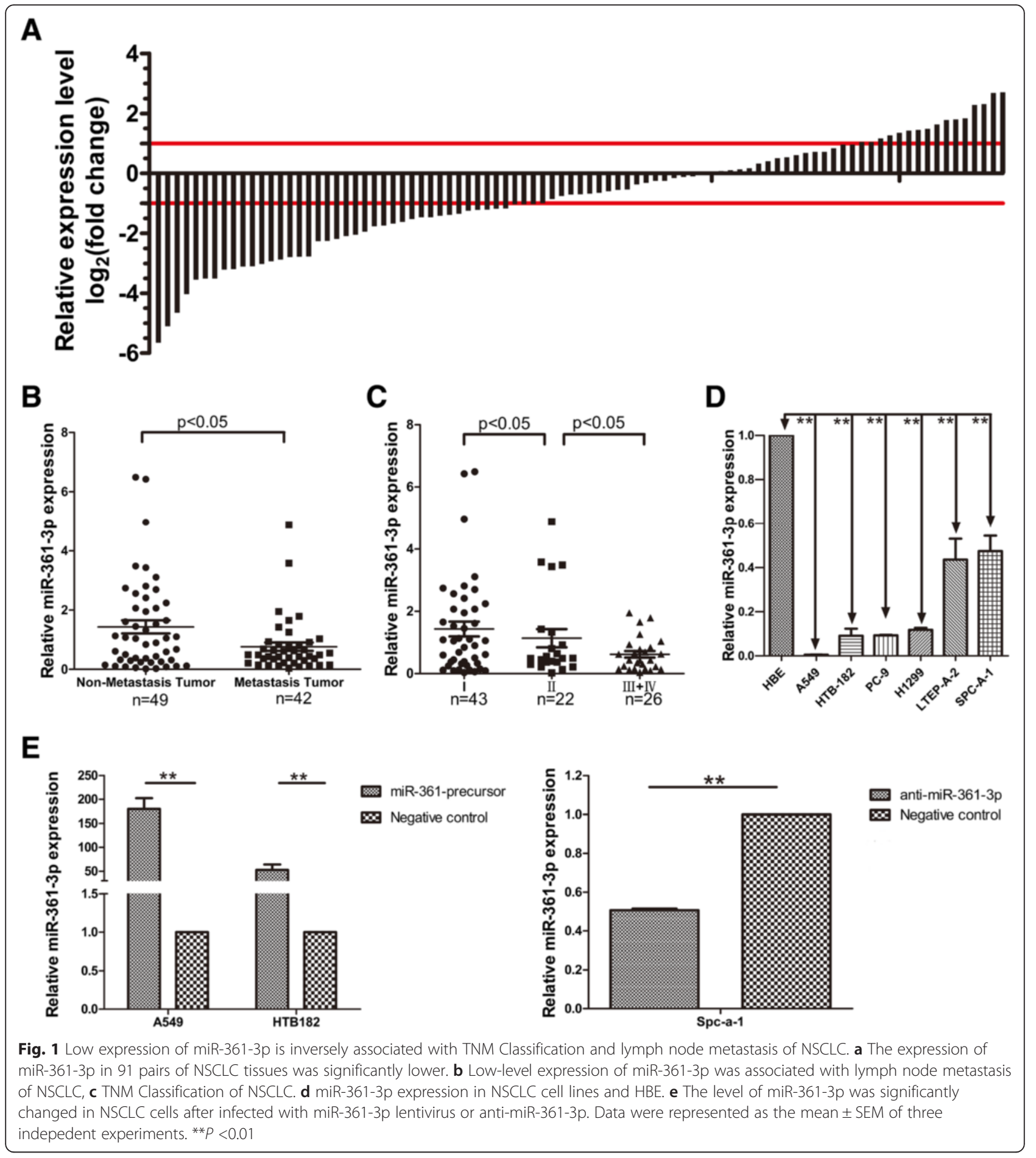

and metastasis in vivo. A549 and HTB-182 cells stably expressing miR-361-3p and negative control vector were injected subcutaneously into nude mice. Palpable tumors formed within 1 week. Tumor volume was measured each week, and mice were sacrificed 4 weeks after tumor cell implantation. The size of NSCLC tumors in these two groups was calculated and compared. The average tumor volume of A549 cells stably transfected with miR361-precursor was significantly smaller than tumors in the negative control group (Fig. 4a). The tumor growthcurve of tumor volume was drawn according to time and a significant difference was shown between the two groups (Fig. 4c). To investigate the in vivo role for miR361-3p in NSCLC cell migration, we examined the mice 
Table 1 miR-361-3p expression and clinicopathological features in non-small cell lung cancer (NSCLC) patients

\begin{tabular}{|c|c|c|c|c|}
\hline \multirow[t]{2}{*}{ Variables } & \multirow[t]{2}{*}{$n$} & \multicolumn{2}{|c|}{ miR-361-3p expression } & \multirow[b]{2}{*}{$p$ value } \\
\hline & & High expression & Low expression & \\
\hline \multicolumn{5}{|l|}{ Gender } \\
\hline Male & 67 & $27(40 \%)$ & $40(60 \%)$ & \\
\hline Female & 24 & $6(25 \%)$ & $18(75 \%)$ & 0.181 \\
\hline \multicolumn{5}{|l|}{ Age(years) } \\
\hline$>55$ & 56 & $20(36 \%)$ & $36(64 \%)$ & \\
\hline$\leqq 55$ & 35 & 13(37\%) & $22(63 \%)$ & 0.890 \\
\hline \multicolumn{5}{|l|}{ Smoking history } \\
\hline Yes & 54 & $20(37 \%)$ & $34(63 \%)$ & \\
\hline No & 37 & 13(35\%) & $24(65 \%)$ & 0.853 \\
\hline \multicolumn{5}{|l|}{ Pathological type } \\
\hline Adenocarcinoma & 54 & 18(34 \%) & $36(66 \%)$ & \\
\hline $\begin{array}{l}\text { Squamous } \\
\text { carcinoma }\end{array}$ & 37 & $15(41 \%)$ & $22(59 \%)$ & 0.482 \\
\hline \multicolumn{5}{|l|}{ Tumor differentiation } \\
\hline High & 22 & $10(45 \%)$ & $22(55 \%)$ & \\
\hline Middle & 58 & $21(36 \%)$ & $37(64 \%)$ & \\
\hline Low & 11 & $2(18 \%)$ & $9(82 \%)$ & 0.307 \\
\hline \multicolumn{5}{|l|}{ Tumor location } \\
\hline Right lung & 45 & 17(38 \%) & $28(62 \%)$ & \\
\hline Left lung & 46 & $16(35 \%)$ & $30(65 \%)$ & 0.766 \\
\hline \multicolumn{5}{|l|}{ Tumor size(cm) } \\
\hline$>3$ & 54 & 17(31\%) & $27(69 \%)$ & \\
\hline$\leqq 3$ & 37 & $16(43 \%)$ & $21(57 \%)$ & 0.252 \\
\hline \multicolumn{5}{|l|}{ Lymphatic metastasis } \\
\hline Yes & 42 & $8(19 \%)$ & $34(81 \%)$ & \\
\hline No & 49 & $23(47 \%)$ & $26(53 \%)$ & 0.002 \\
\hline \multicolumn{5}{|l|}{ TNM classification } \\
\hline 1 & 43 & $22(51 \%)$ & $21(49 \%)$ & \\
\hline$\|$ & 22 & $6(27 \%)$ & $16(73 \%)$ & \\
\hline$I I I+I V$ & 26 & $5(19 \%)$ & $21(81 \%)$ & 0.017 \\
\hline
\end{tabular}

Abbreviations: TNM tumor-node-metastasis

${ }^{*} x^{2}$ test

for lung metastasis of the A549 cells. As shown in Fig. 4, Immunohistochemistry confirmed that the expression of SH2B1 was significantly lower in A549 miR-361-precursor group than negative control groups (Fig. 4d). The intrapulmonary metastasis rate of A549 vector was $80 \%$, whereas no metastasis was found in A549 miR-361-precursor group (Fig. 4b, d). Together, these data support an important role formiR-361-3p in suppression of NSCLC growth and metastasis in vivo.

\section{SH2B1 is a direct downstream target of miR-361-3p}

To explore the molecular mechanisms through which miR-361-3p regulates NSCLC cell proliferation and metastasis, we searched candidate target genes of miR361-3p using publicly available databases. Among the candidates, SH2B1 exhibited one of the highest prediction scores and the most complementary structure with miR-361-3p (Fig. 5a). Moreover up-regulation of SH2B1 protein was found in various types cancer and high SH2B1 expression is associated with more aggressive phenotypes [18-20]. We then carried out a luciferasebased assay to validate whether these genes were indeed regulated by miR-361-3p. Luciferase vectors containing the 3'-UTR of each gene were created and transfected along with or without the miR-361-3p expressing plasmid into cells. Measurement of luciferase activity revealed that miR-361-3p expression was associated with marked reduction of the activity of SH2B1 UTR. The specificity of this inhibition was demonstrated by the finding that the activity of a mutant SH2B1 3'-UTR with the putative binding site mutated was not affected by miR-361-3p (Fig. 5b). In addition, western blot analysis showed that SH2B1 protein expression was clearly decreased in A549 cells and HTB-182 cells transfected with LV-miR-361-precursor, and increased in SPC-A-1 cells transfected with LV-anti-miR-361-3p (Fig. 5c). Furthermore, to explore the relationship between miR-361$3 \mathrm{p}$ and SH2B1 in clinical specimens, we examined SH2B1 expression using immunohistochemical analysis on FFPEs of 91 NSCLC specimens. SH2B1 expression was positively correlated with TNM stage and lymph node metastasis of NSCLC $(P<0.001)$ (Table 2). We compared SH2B1 expression data from immunohistochemistry analysis with results of miR-361-3p expression level from qRT-PCR analysis on specimens of these NSCLC tissues. There was an inverse correlation between miR-361-3p and SH2B1 expressions in these specimens (Fig. $5 \mathrm{~d}$, e, $R=-0.622, P<0.001$ ). Taken together, these results indicated that $\mathrm{SH} 2 \mathrm{~B} 1$ was a direct downstream target for miR-361-3p in NSCLC cells.

\section{Gain- and loss-of-function of SH2B1 abrogated or mimicked impact of miR-361-3p on cell proliferation and metastasis}

To determine whether miR-361-3p-dependent inhibition of NSCLC cell proliferation and metastasis was indeed mediated by $\mathrm{SH} 2 \mathrm{~B} 1$, we used a complementary approach of gain- and loss-of-function of SH2B1. Specifically we transfected with si-SH2B1 to down the expression of SH2B1, and transfected with a SH2B1 expression vector to restore SH2B1 expression. The restoration of SH2B1 expression enhanced the proliferation (Fig. 6a) and colony formation (Fig. 6b) of A549 $9^{\text {miR-361-precursor }}$ and HTB-

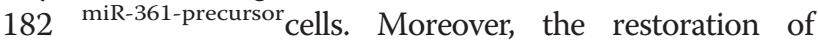
SH2B1 significantly attenuated miR-361-3p-mediated inhibition of A549 $9^{\text {miR-361-precursor }}$ and HTB-182 miR-361-precursor cells migration and invasion (Fig. 7a, b). In contrast, 


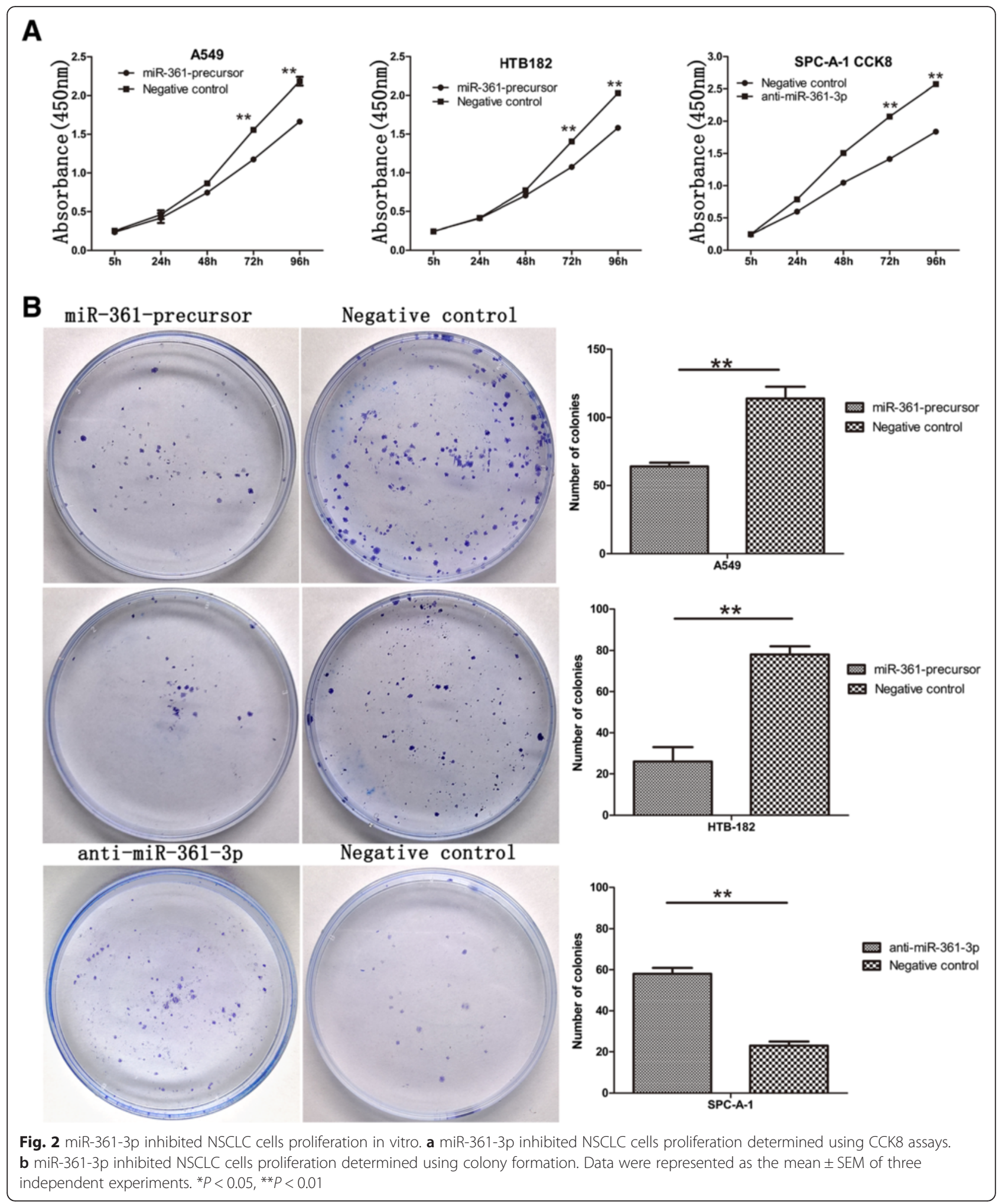

siSH2B1-mediated inhibition of SH2B1 expression mimicked the effect of miR-361-3p on proliferation and colony formation capacity in SPC-A-1 cell ${ }^{\text {anti-miR-361-3p }}$ (Figs. 6a, b and 7c).
We further investigated the role of SH2B1 in NSCLC progression. The results showed that $\mathrm{SH} 2 \mathrm{~B} 1$ overexpression significantly promoted wound healing of SPC-A1cells (Fig. 7a). Downregulation of SH2B1 on the other 


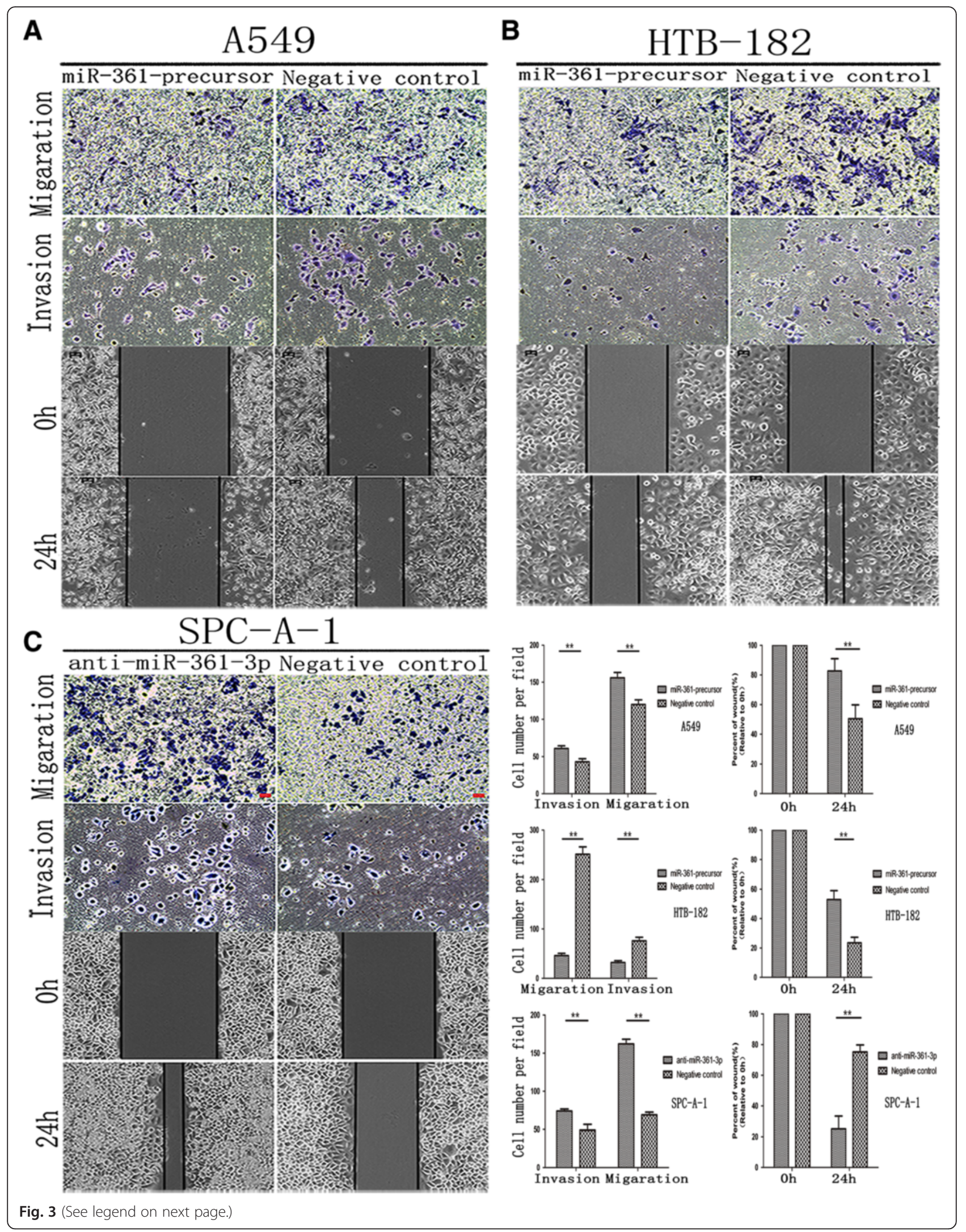


(See figure on previous page.)

Fig. 3 miR-361-3p inhibited NSCLC migration and invasion in vitro. a up-regulated miR-361-3p suppressed migration and invasion in vitro in A549. $\mathbf{b}$ up-regulated miR-361-3p suppressed migration and invasion in vitro in HTB-182. c down-regulated miR-361-3p enhanced migration and invasion in vitro in SPC-A-1 compared with controls. Data which were put beside picture $\mathbf{c}$ were represented as the mean \pm SEM of three independent experiments. ${ }^{*} P<0.05,{ }^{* *} P<0.01$

hand inhibited the proliferation (Fig. 6a), cell migration and invasion of A549 (Fig. 7a) and HTB-182 cells (Fig. 7b). These results together support an oncogenic role of SH2B1 in NSCLC.

To explore whether miR-361-3p exerts its functions through the JAK2-SH2B1-Rac1 pathways that contribute to cancer proliferation, development and progression [20], we examined a number of the main SH2B1 signaling downstream target genes, including phosphorylation of Janus kinases 2(p-JAK2), phosphorylation of Rho GTPase Ras-related C3 botulinum toxin substrate 1(pRac1), cAMP-Protein Kinase Catalytic subunit (PKA), matrix metalloproteinase-2(MMP2), and MMP9. Overexpression of p-JAK2, PKA, MMP2 and MMP9 and downexpression of p-Rac1 were detected in A549 and HTB-182 cells that stably overexpressed miR-361-3p (Fig. 7d, lane 1-2). In contrast, downexpression of p-JAK2, PKA, MMP2 and MMP9 and overexpression of p-Rac1 were detected in SPC-A-1 cells with stable down-regulation of miR-361-3p SH2B1 exhibited lower SH2B1 expression (Fig. 7d, lane 3). These data indicate that miR-361-3p inhibits SH2B1 signaling in NSCLC, which involved tumor development and progression.

\section{Discussion}

NSCLC is the most prevalent cancer types and has highest mortality rate in China [1]; however, the progression mechanisms of NSCLC have largely remained elusive. Ample evidence indicates a crucial role for miRNAs in human cancer [21], especially the miRNAs participate in the initiation, promotion, and progression of NSCLC. For instance, miR-21 promotes growth and invasion of NSCLC [22]. In addition, miR-494, miR-101, miR-1254, miR-574-5p, miR-143 and miR-181a were demonstrated to be involved in NSCLC [23-25]. In the present study, we certified that miR-361-3p was frequently down-regulated in NSCLC, and first found that the reduced miR-361-3p expression was closely related to advanced stage and lymph node metastasis of NSCLC. Furthermore, we demonstrated that overexpression of miR-361-3p could suppress NSCLC cell proliferation, migration and invasion in vitro and in vivo. The versatile functions of miR-361-3p in tumor cell proliferation, migration and invasion suggest its potential application as a prognostic predictor and cancer therapeutic target.
SH2B1, which is an Src homology 2 (SH2) and pleckstrin homology $(\mathrm{PH})$ domain-containing protein, is known an adapter protein, and can bind the large number of kinases, such as Janus kinase (JAK)-2 and JAK1 [26]; fibroblast growth factor receptor-1 [27]; insulin receptor [28]; insulin receptor substrate-1 [29]. It was reported that $\mathrm{SH} 2-\mathrm{B} \beta$ functions as an adapter/scaffolding protein that recruits Rac and perhaps other proteins to activated membrane receptor-JAK complexes or receptor tyrosine kinases where they are then positioned appropriately to regulate the actin cytoskeleton and promote membrane ruffling and cell motility [20]. In our study, we demonstrated that miR-361-3p can bind to a sequence within the 3'-UTR of SH2B1 by luciferasebased reporter assay. MiR-361-3p-mediated control of SH2B1 expression was further validated by complementary gain- and loss-of-function approaches. Importantly, ectopic SH2B1 expression could effectively impede the ability of miR-361-3p to inhibit proliferation and metastasis. Moreover, knockdown expression of SH2B1 abrogated the effects induced by miR-361-3p-inhibitor. Our study provides solid evidence to support that miR-361$3 p$ inhibit proliferation and metastasis of NSCLC by directly targeting SH2B1. For further study, we examined the expression of SH2B1 signaling downstream target genes and found that expression of p-JAK2, PKA, MMP2 and MMP9 were decreased and p-Rac1 was increased in NSCLC cells that stably overexpressed miR-361-3p. In contrast, expression of p-JAK2, PKA, MMP2 and MMP9 was significantly up-regulated and p-Rac1was down-regulated in NSCLC cells that stably expressed miR-361-3p inhibitor. This suggests that SH2B1 activation resulted in increasing migration and invasion is likely through activation of JAK2/Rac1 that regulates cell morphology and mobility as well as membrane trafficking. Rac1 is a member of the Rho family of small GTPases and participates in numerous pathways inducing cytoskeleton reorganization, gene transcription, cell proliferation and survival $[30,31]$, especially in lung cancer modifies lung cancer migration, invasion and actin cytoskeleton rearrangements and enhances chemosensitivity to antitumor drugs [32, 33]. Schwarz J et al. reported that phosphorylation of Rac1 at serine-71 affects Rac1 activity by shift specificity of GTPase/effector coupling and modulates downstream signaling [34]. Thus, downregulation of $\mathrm{p}$-Rac1 through inhibition of SH2B1 


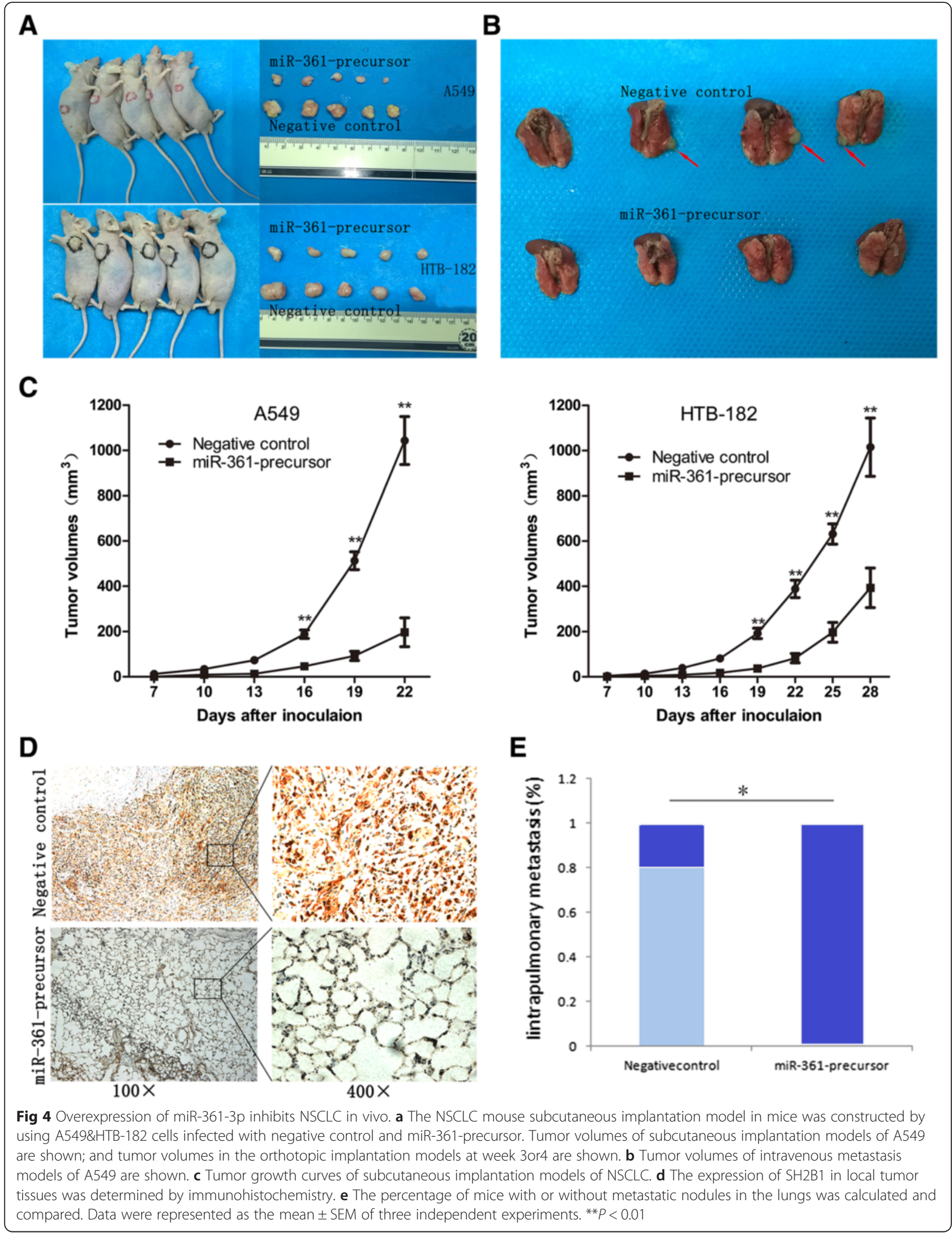




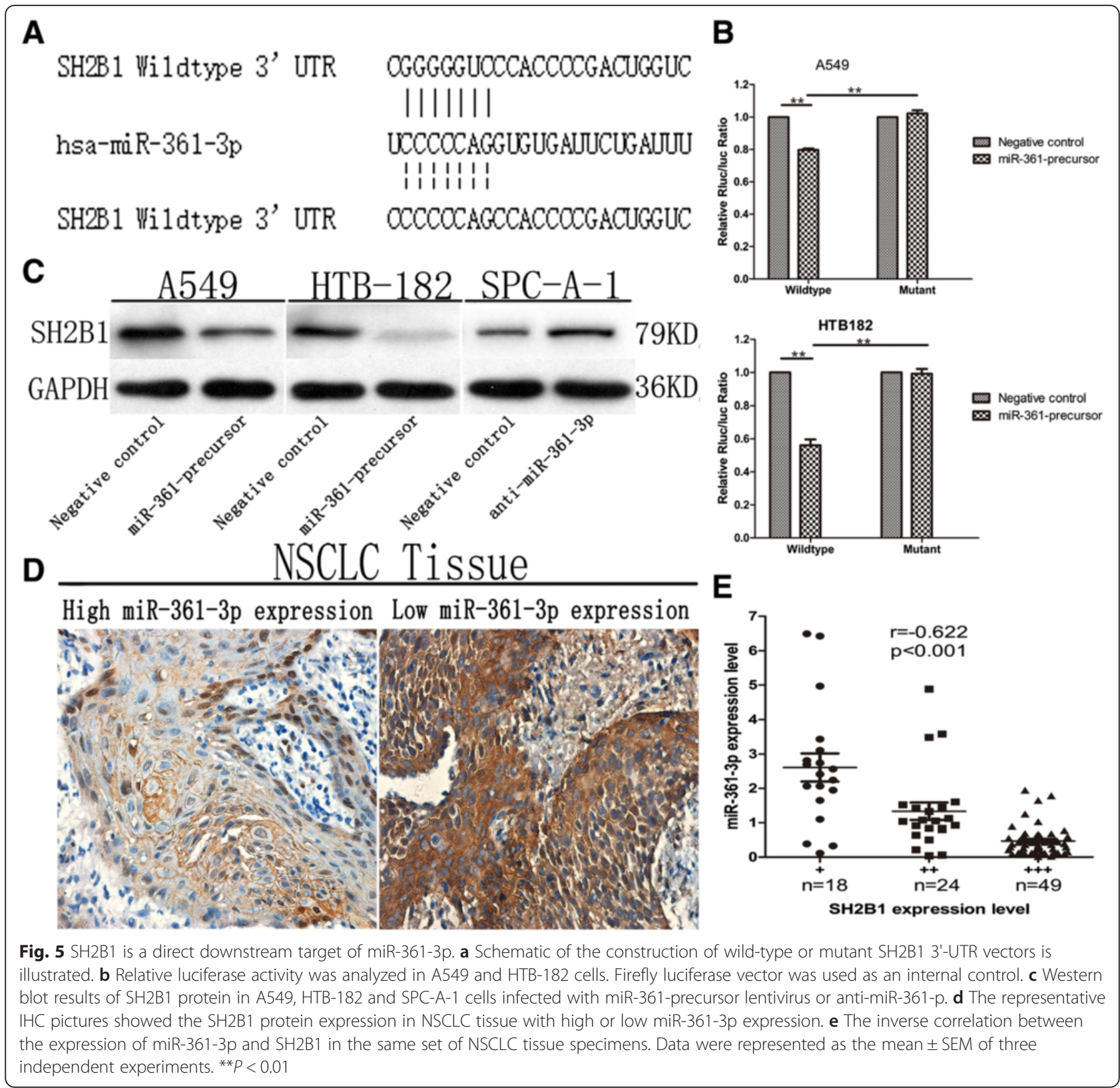

could be a mechanism by which miR-361-3p suppresses cell proliferation, migration and invasion. MMPs are a family of enzymes that proteolytically degrade various components of the extracellular matrix [35]. High levels of certain MMPs are closely correlated with the invasive and metastatic potential of tumors [36, 37]. Specifically, activated Rac1 regulates tumor invasion of lung cancer cells by regulating gene transcription of MMP2 and MMP9 [38]. These data indicate that miR-361-3p suppresses progression of NSCLC through inhibition of the versatile tumorpromoting SH2B1. It is noteworthy that neither miR361-3p nor SH2B1 has been investigated in NSCLC.
Our report revealed a novel miR-361-SH2B1 axis in regulation of NSCLC.

SH2B1 is identified as a target of miR-361-3p, but SH2B1 might not solely be explained the antioncogenic properties of miR-361-3p, because a single miRNA can potentially regulate dozens to hundreds of genes in tumorigenesis [39]. Therefore, future studies to identify additional novel targets of miR-361-3p and other miRNAs that can also regulate SH2B1 will allow us to have deep understanding of the mechanisms underlying the development and progression of NSCLC.

In conclusion, our results show that miR-361-3p is significantly downregulated in NSCLC. This miRNA can 
Table 2 SH2B1 expression and clinicopathological features in non-small cell lung cancer (NSCLC) patients

\begin{tabular}{|c|c|c|c|c|c|}
\hline \multirow[t]{2}{*}{ Variables } & \multirow[t]{2}{*}{$n$} & \multicolumn{3}{|c|}{ SH2B1 expression } & \multirow[b]{2}{*}{$p$ value* } \\
\hline & & + & ++ & +++ & \\
\hline \multicolumn{6}{|l|}{ Gender } \\
\hline Male & 67 & 16 & 16 & 35 & \\
\hline Female & 24 & 3 & 6 & 15 & 0.486 \\
\hline \multicolumn{6}{|l|}{ Age(years) } \\
\hline$>55$ & 56 & 14 & 10 & 32 & \\
\hline$\leqq 55$ & 35 & 5 & 12 & 18 & 0.156 \\
\hline \multicolumn{6}{|l|}{ Smoking history } \\
\hline Yes & 54 & 14 & 11 & 29 & \\
\hline No & 37 & 5 & 11 & 21 & 0.293 \\
\hline \multicolumn{6}{|l|}{ Pathological type } \\
\hline Adenocarcinoma & 54 & 15 & 12 & 27 & \\
\hline Squamous carcinoma & 37 & 4 & 10 & 23 & 0.063 \\
\hline \multicolumn{6}{|l|}{ Tumor differentiation } \\
\hline High & 22 & 7 & 6 & 9 & \\
\hline Middle & 58 & 10 & 14 & 34 & \\
\hline Low & 11 & 2 & 2 & 7 & 0.518 \\
\hline \multicolumn{6}{|l|}{ Tumor location } \\
\hline Right lung & 45 & 11 & 10 & 24 & \\
\hline Left lung & 46 & 8 & 12 & 26 & 0.696 \\
\hline \multicolumn{6}{|l|}{ Tumor size(cm) } \\
\hline$>3$ & 54 & 8 & 12 & 34 & \\
\hline$\leqq 3$ & 37 & 11 & 10 & 16 & 0.129 \\
\hline \multicolumn{6}{|l|}{ Lymphatic metastasis } \\
\hline Yes & 42 & 0 & 10 & 32 & \\
\hline No & 49 & 19 & 12 & 18 & $<0.001$ \\
\hline \multicolumn{6}{|l|}{ TNM classification } \\
\hline I & 43 & 18 & 10 & 15 & \\
\hline$\|$ & 22 & 1 & 9 & 12 & \\
\hline$I I I+I V$ & 26 & 0 & 3 & 23 & $<0.001$ \\
\hline
\end{tabular}

potently inhibit NSCLC cell proliferation and metastasis in vitro and in vivo. The tumor-suppressive role of miR$361-3 p$ is largely mediated by one of its target, Sh2B1. These findings provide new insight into the molecular pathogenesis of NSCLC and implicate miR-361-3p as a potential prognostic biomarker and therapeutic target of NSCLC.

\section{Conclusions}

Carcinogenesis is a series of sequential events, including growth, proliferation, migration, and local invasion. Herein, we showed that miR-361-3p could suppress the carcinogenesis of NSCLC through inhibition of growth, proliferation, migration and invasion. Furthermore, our evidence suggests that miR-361-3p is a potential therapeutic target in NSCLC. Further studies are required to fully understand the detailed mechanisms of miR-361-3p in NSCLC carcinogenesis and as a potential therapeutic approach.

\section{Methods}

Ethical statement

Written informed consent was obtained from all participants, and the study protocol was approved by the ethics committee of Xiangtan Hospital, Central South University (CSU). All mouse experiments were approved by the Animal Care and Use Committee and conducted in accordance with the official recommendations of the Care and Use Laboratory Animals of Xiangtan Hospital, CSU.

\section{Patient and tissue samples}

Primary cancer tissues and paired adjacent non-tumor tissues were collected from 91 patients with NSCLC underwent lung resection at the Department of Surgery, Xiangtan Hospital of Central South University from March 2013 to June 2014. Patients did not receive any preoperative cancer treatments, such as radiotherapy or chemotherapy. Each specimen was rapidly frozen in liquid nitrogen, and transferred to the $-80{ }^{\circ} \mathrm{C}$ refrigerator for subsequent experiments. The collected samples were confirmed by an experienced pathologist. The clinical data of NSCLC patients including tumor-node metastasis (TNM) staging were also collected.

\section{Cell lines and cell culture}

Six NSCLC cell lines (HTB-182, A549, SPC-A-1, H1299, PC-9, LTEP-A-2) were obtained from the American Type Culture Collection. A normal human bronchial epithelial cell line (HBE), were purchased from the Institute of Biochemistry and Cell Biology of the Chinese Academy of Sciences (Shanghai, China). Cells were cultured in RPMI 1640 (GIBCO-BRL) medium supplemented with $10 \%$ fetal bovine serum (10 \% FBS), 100 $\mathrm{U} / \mathrm{ml}$ penicillin, and $100 \mu \mathrm{g} / \mathrm{ml}$ streptomycin (Biyuntian, China) in humidified air at $37^{\circ} \mathrm{C}$ with $5 \% \mathrm{CO} 2$.

\section{RNA extraction and qRT-PCR analyses}

Total RNA was extracted from cell lines and frozen tumor specimens using Trizol reagent (Invitrogen, Carlsbad, CA, USA) according to the manufacturer's protocol. The qRT-PCR assays were performed to detect miR-361-3p and SH2B1 expression using the PrimeScript RT reagent Kit and SYBR Premix Ex Taq (GeneCopoeia, USA) according to the manufacturer's instructions. The relative level of miR-361-3p and SH2B1 was determined by qRT-PCR using gene specific primers. U6 or $\beta$-actin was used as a normalization 


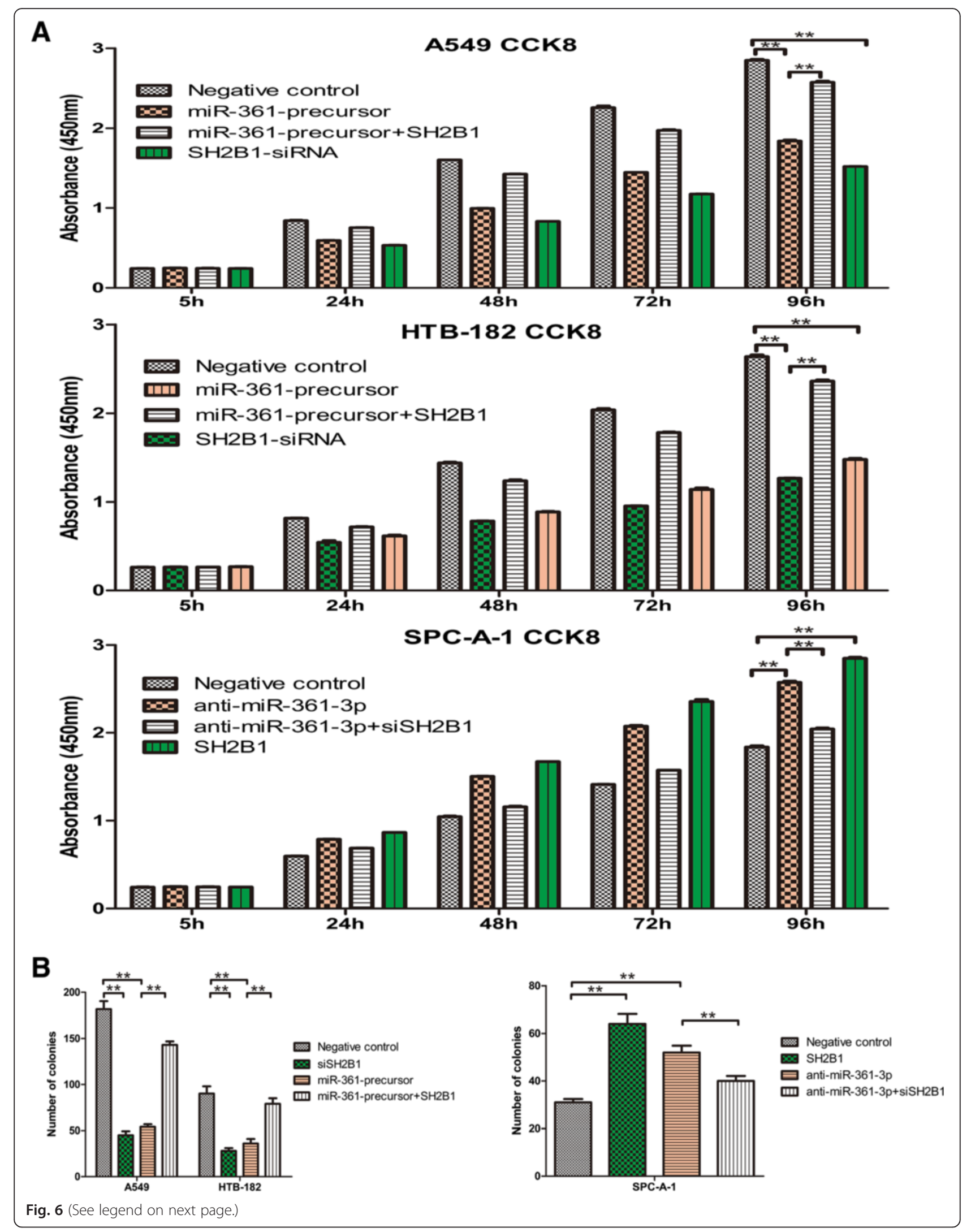


(See figure on previous page.)

Fig. 6 Gain- and loss-of-function study with SH2B1 expression vector and siSH2B1 in cells proliferation in vitro. To investigate whether SH2B1 expression may interfere or mimic the function of miR-361-3p, NSCLC cells were transfected by SH2B1 siRNA or SH2B1 expression vector to inhibit or restore the $\mathrm{SH} 2 \mathrm{~B} 1$ expression. CCK8 assay (a), colony formation (b). Data were represented as the mean \pm SEM of three independent experiments. ${ }^{*} P<0.05,{ }^{*} P<0.01$

control. Levels of miR-361-3p and SH2B1 were normalized to $\mathrm{U} 6$ and $\beta$-actin, respectively, to yield a $2^{-\Delta \Delta \mathrm{Ct}}$ value for relative expression of each transcript. Experiments were repeated at least three times. The RT reaction was carried out under the following conditions: $37{ }^{\circ} \mathrm{C}$ for $60 \mathrm{~min} ; 85^{\circ} \mathrm{C}$ for $5 \mathrm{~min}$; and then held on $4{ }^{\circ} \mathrm{C}$. After the RT reaction, the complementary DNA products were diluted at $1: 5$ and $2 \mu \mathrm{l}$ of the diluted complementary DNA was used for subsequent qRT-PCR reactions. The qRTPCR primers were designed as follows: miR-361-3p, Forward: 5'-UCCCCCAGGUGUGAUUCUGAUUU-3', Reverse: 5' -GCAAATCAGAATCACACCTG-3'. U6, Forward: 5'-CTCGCTTCGGCAGCACA-3', Reverse: 5' -AA CGCTTCACGAATTTGCGT-3'; Human SH2B1, Forward: 5'-GACAACCACAGCCCTGGAGAT-3', Reverse: 5'-AGACACCCAGGCCTTCACAT-3'. Human $\beta$-actin, Forward: 5'-GCACCACACCTTCTACAATGAG-3', Reverse: 5'-GATAGCACAGCCTGGATAGCA-3'. Human GAPDH, Forward: 5' - TGCACCACCAACTGCTTAG C-3', Reverse: 5'-GGCATGGACTGTGGTCATGAG-3'. The qRT-PCR reaction was conducted at $95^{\circ} \mathrm{C}$ for $10 \mathrm{~min}$ and followed by 40 cycles of $95{ }^{\circ} \mathrm{C}$ for $10 \mathrm{~s}, 60{ }^{\circ} \mathrm{C}$ for $30 \mathrm{~s}$ and $72{ }^{\circ} \mathrm{C}$ for $30 \mathrm{~s}$ in the ABI 7500 real-time PCR system (Applied Biosystems, CA, USA). The qRT-PCR results were analyzed and expressed as relative miRNA expression of CT (threshold cycle) value, which was then converted to fold changes.

\section{Vector construction and transfection}

The hsa-mir-361-precursor sequence was constructed as follows: (Forward) hsa-miR-361-Age I-F GAGGATCC CCGGGTACCGGTGCAGTGGCACGCTTGACAGTG ATTTTTTTCCTGGGATTTGGGAGC, (Reverse) hsamiR-361-Nhe I-R CACACATTCCACAGGCTAGTA GGGAGCTCAACCATACCAG. The sequence was amplified and cloned into the pGC-FU-3FLAG-SV40-EGFP Vector (GeneChemCo., Shanghai, China) to generate pGC-FU-miR-361 and the pGC-FU-3FLAG-SV40-EGFP Vector only as negative control. The hsa-miR-361-3p-inhibition sequence was constructed as follows: (Forward) hsa-miR-anti-361-3p-AgeI-F AATTCAAAAATCCCCCA GGTGTGATTCTGATTT, (Reverse) hsa-miR-anti-361-3p -EcoRI-R CCGGAAATCAGAATCACACCTGGGGGA TTTTTG. The sequence was amplified and cloned into the pGCSIL-008 Vector to generate pGCSIL-008-miRanti-361-3p. The non-silencing shRNA control sequences (TTCTCCGAACGTGTCACGT) was cloned into the
pGCSIL-008 Vector as negative control (pGCSIL-008RNAi-NC-LV). The SH2B1 expression vector was constructed by inserting its CDS sequence into the pEX-2 vector (GeneChem, Shanghai, China). Virus packaging, production and cell transfection were performed according to the manufacture's protocol. The expression was validated by qRT-PCR. SH2B1-siRNA (si-SH2B1) and nonspecific control siRNA (si-NC) were purchased from GeneChem, Shanghai, China.

\section{Cell proliferation and colony formation assays}

Cell proliferation was monitored using CCK8 (Sigma). LV-miR-361-precursor, LV-negative control transfected A549 and HTB-182 or anti-miR-361-3p, or pGC FURNAi-NC-LV (Negative control) transfected SPC-A-1 cells (3000 cells/well, 5 wells/group) were allowed to grow in 96-well plates. Cell proliferation was documented every $24 \mathrm{~h}$ following the manufacturer's protocol. CCK-8 reagent was added to each well at $1.5 \mathrm{~h}$ before the endpoint of incubation. The optical density (OD) $450 \mathrm{~nm}$ values were determined by a microplate reader. All experiments were repeated at least three times. For the colony formation assay, LV-miR-361-precursor, LV-negative control transfected A549 and HTB182 cells or LV-anti-miR-361-3p, pGC FU-RNAi-NC-LV (Negative control) transfected SPC-A-1 cells (100/well) were allowed to grow in culture dish $\left(8 \mathrm{~cm}^{2}\right)$ and maintained in media containing $10 \%$ FBS, replacing the medium every 4 days. After 14 days, cells were fixed with methanol and stained with $10 \%$ Giemsa (Solarbio, Beijing, China). Only positive colonies (diameter $>40$ um) in the dishes were counted and compared [40]. All experiments were performed in triplicate.

\section{In vitro cell migration and invasion assays}

For the migration assays, $48 \mathrm{~h}$ after transfection, $2 \times 10^{4}$ cells in serum-free media were placed into the upper chamber of an insert $(8 \mu \mathrm{m}$ pore size, $\mathrm{BD})$. For the invasion assays, $4 \times 10^{4}$ cells in serum-free media were placed into the upper chamber of an insert coated with Matrigel (BD, USA). Media containing $10 \%$ FBS were added to the lower chamber. For migration assays, after $24 \mathrm{~h}$ of incubation, and for invasion assays, after $24 \mathrm{~h}$ of incubation, removing the cells remaining on the upper membrane with cotton wool, whereas the cells that had migrated or invaded through the membrane were stained with $10 \%$ Giemsa in methanol, imaged, and 


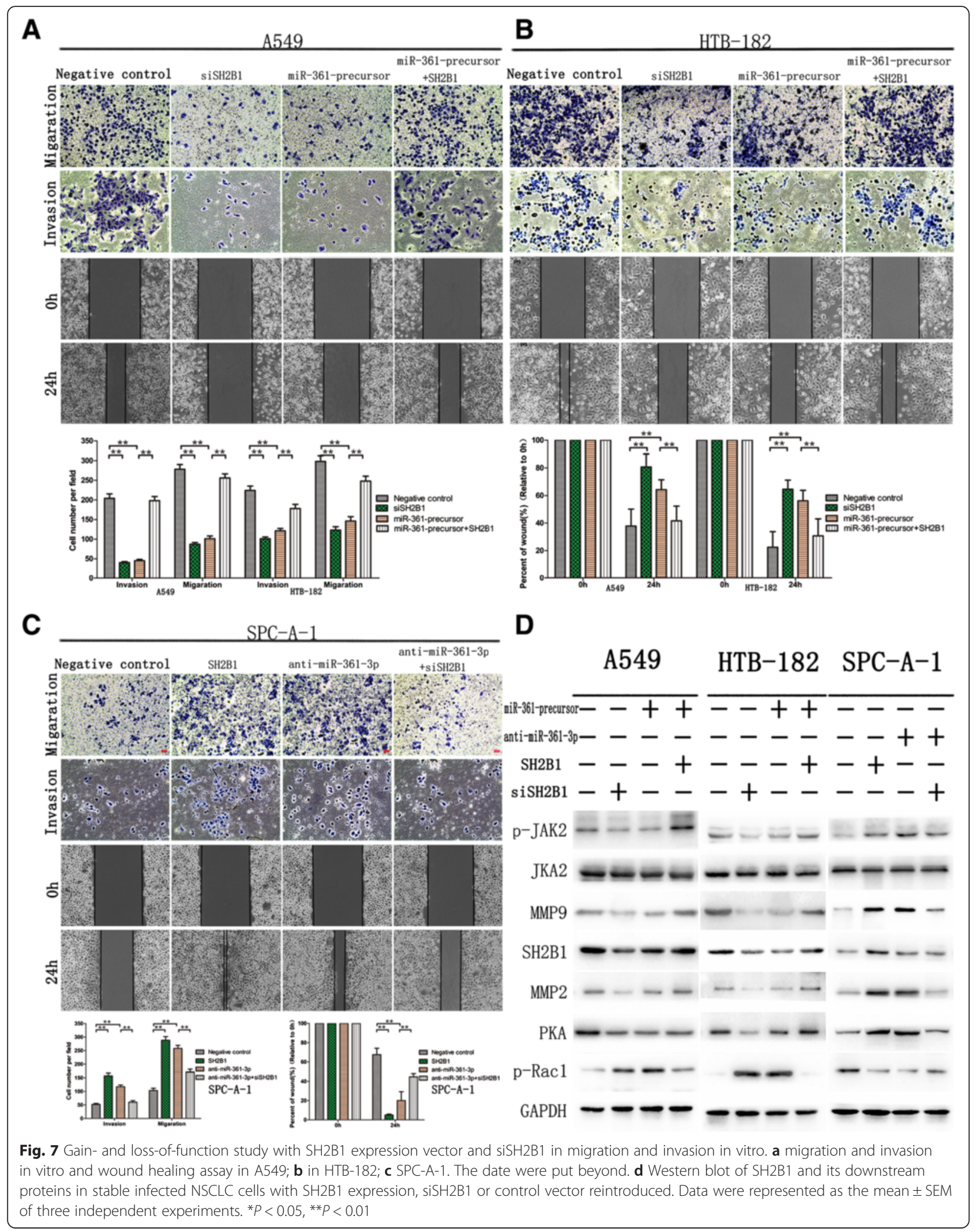


counted using an inverted microscope (Canon, Japan). For wound-healing assay, cells $\left(1 \times 10^{6}\right.$ cells $)$ were seeded in six-well plates, cultured overnight and transfected with miR-361-precursor, negative control or antimiR-361-3p, pGC FU-RNAi-NC-LV (Negative control). Upon reaching the 95-100 \% confluence, the cell layer was scratched with a $10 \mu \mathrm{l}$ pipette tip and washed with culture medium twice and cultured again for up to $24 \mathrm{~h}$ with serum-free medium. Images were captured at different time points $(0,24 \mathrm{~h})$ and the same areas under a microscope to assess the rate of gap closure. The wound width of 6 random views was measured, and the healing width was calculated by wound width at $0 \mathrm{~h}$ time point minus wound width at $24 \mathrm{~h}$ time point and normalized by solvent control [41]. Every experiment was repeated three times. Bioinformatics methods using bioinformatics software (DIANA TOOL, Targetscan, miRanda) to predict miR-361-3p potential target gene, combined with the literature and through the test screening, SH2B1 was selected as a further object of study.

\section{Luciferase reporter assay}

To construct a luciferase reporter vector, SH2B1 3'UTR fragment containing putative binding sites for miR361-3p was amplified by PCR using the following primers: h-SH2B1-F: GCGCTCGAGCTATCCAGAAC CGACCACC h-SH2B1-R:AATGCGGCCGCCACGAT

AGAACCGAGATAA, the PCR product was subcloned downstream of the luciferase gene in the pLUC Luciferase vector (Ruibo, Guangzhou,China) and named SH2B1-3'UTRWT.For the mutated construct, using the following primers: h-SH2B1-mut-F:GCCCCACCGACCCCC CCATTTCCCCATTAACTA. h-SH2B1-mut-R: GGAA ATGGGGGGGTCGGTGGGGCTGACCAGAAG.A549miR-361-precursor and HTB-182 $2^{\text {miR-361-precursor }}$ cells grown in 96-well plate were transfected with $100 \mathrm{ng}$ of SH2B1-3'UTR-Wt or SH2B1-3'UTR-Mut, using the Lipofectamie 3000 (Invitrogen, USA). After $72 \mathrm{~h}$ of transfection, luciferase activity was assessed according to the Dual-Luciferase Reporter Assay protocol (Promega, Madison, WI). Each experiment was repeated in triplicates.

\section{Western blotting}

Total protein was extracted by lysing cells in RIPA buffer containing protease inhibitor. Protein samples were separated by sodium dodecyl sulfate polyacrylamide gelelectrophoresis (SDS-PAGE) and transferred onto polyvinylidenefluoride (PVDF) membranes. After blocking with $5 \%$ non-fat milk or $3 \%$ BSA in TBS-T, membranes were incubated with the primary antibody. The following antibodies were used: SH2B1 (1:1000,Abcam, USA), JAK2 (1:600, Abcam, USA), p-JAK2 (1:2000, Abcam, USA), p-Rac1 (1:500, Abcam, USA), Anti-cAMP Protein
Kinase Catalytic subunit (1:60000,Abcam,USA),MMP2 (1:2000,Abcam.,USA), MMP9 (1:1000, Abcam,USA), GAPDH (1:10000, Abcam, USA) and goat-anti-rabbit IgG conjugated to horseradish peroxidase (HRP) (1:5000, Santa Cruz, USA), which was used as the secondary antibody. Cells were seeded on $10 \mathrm{~cm}$ cell culture plates, grown to $80 \%$ confluences, and serum starved overnight. Target signals were quantified by BandScan software (Bio-Rad, Hercules, CA) and defined as the ratio of target protein relative to GAPDH.

\section{NSCLC mouse model}

Five-week-old BALB/C-nu nude male mice were used for animal studies, and all animals were maintained in the specific pathogen-free (SPF) conditions at our institution. For the in vivo tumor proliferation assay, $3 \times 10^{6}$ A549 cells transfected with LV-miR-361-precursor or LV-negative control were injected subcutaneously into the nude mice ( 5 per group). Tumor growth was monitored by caliper measurement once or twice a week for at least 4 weeks. Tumor volume was calculated as follows: $\mathrm{V}=\mathrm{L} \times \mathrm{l}^{2} \times 0.5$, where $\mathrm{L}$ and 1 represent the larger and the smaller tumor diameters, respectively. The mice were sacrificed after 4 weeks. For the in vivo tumor metastasis assay, $2 \times 10^{6}$ A549 cells transfected with LVmiR-361-precursor or LV-negative control were injected by the tail vein into the nude mice ( 5 per group). The mice were sacrificed after 2 months. At the time of killing the lung were removed and immediately fixed in $4 \%(\mathrm{w} / \mathrm{v})$ paraformaldehyde overnight and treated for immunohistochemistry.

\section{Immunohistochemical staining}

Formalin-fixed, paraffin-embedded tissues were cut into $4-\mu \mathrm{m}$ sections. Following deparaffinization, sections were rehydrated and subjected to antigen retrieval by microwaving in $0.01 \mathrm{M}$ sodium citrate ( $\mathrm{pH}$ 6) for $10 \mathrm{~min}$. Sections were incubated at $4{ }^{\circ} \mathrm{C}$ overnight with monoclonal antibodies against SH2B1 as mentioned above. Immunostaining was performed using ChemMate DAKO EnVision Detection Kit, Peroxidase/DAB, Rabbit/Mouse (code K5007, DakoCytomation, Glostrup, Denmark) according to the manufacturer's instructions [42]. Subsequently, sections were counterstained with hematoxylin (Dako) and mounted in dimethyl benzene. Protein staining was evaluated under a light microscope at $100 \times$ and $400 \times$ magnification. Staining intensity was scored manually by two independent experienced pathologists as $0=$ no staining, $1=$ weak staining, $2=\bmod -$ erate staining, and $3=$ strong staining. Tumor cells in five fields were randomly selected and scored based on the percentage of positively stained cells $(0-100 \%)$, as follows: 0 , less than $5 \% ; 1,5$ to $25 \%$; 25 to $50 \%$; or 3 , more than $50 \%$. The final ICH score was then 
calculated by adding the two above scores, and scores of $0-2$ were considered as low expressions while scores of 3-6 were defined as high expressions [43, 44].

\section{Statistical analysis}

The relationship between miR-361-3p expression and clinicopathologic parameters was analyzed using the Pearson $\chi^{2}$ test. Spearman's correlation analysis was used to determine correlation between miR-361-3p and SH2B1 expression. The differences between groups were analyzed using Student $t$ test when there were only two groups, or assessed by one-way ANOVA when there were more than two groups. All statistical analyses were performed using the SPSS software (version 19.0, Chicago, IL). A two-tailed value of $P<0.05$ was considered statistically significant.

\section{Competing interests}

The authors report no conflicts of interest. The authors are solely responsible for the content and writing of this paper.

\section{Authors' contributions}

CW contributed to analysis and interpretation of data and drafting of the manuscript. LS contributed to acquisition of data and technical support. WS and WJ contributed to acquisition of data and technical support. ZW contributed to analysis and interpretation of data. CY contributed to acquisition of data and technical support and revised the manuscript for important intellectual content. DC contributed to technical support and revised the manuscript for important intellectual content. ZC contributed to study concept and design, analysis and interpretation of data and drafting of the manuscript. All authors read and approved the final manuscript.

\section{Acknowledgments}

This work was supported by grants from the National Natural Scientific Foundation of China (Nos. 81372515, 81401901).

\section{Author details}

'Department of Thoracic Surgery, Xiangya Hospital, Central South University, Xiangya Road 87th, Changsha 410008, Hunan, PR China. ${ }^{2}$ Key Laboratory of Cancer Proteomics of Chinese Ministry of Health, Institute of Medical Sciences, Xiangya Hospital, Central South University, Xiangya Road 87th, Changsha 410008, Hunan, PR China. ${ }^{3}$ Department of Urology Surgery, Xiangya Hospital, Central South University, Xiangya Road 87th, Changsha 410008, Hunan, PR China.

Received: 24 March 2016 Accepted: 5 May 2016

Published online: 10 May 2016

\section{References}

1. Chen W, Zheng R, Baade PD, Zhang S, Zeng H, Bray F, Jemal A, Yu XQ, He J. Cancer statistics in China, 2015. CA Cancer J Clin. 2016;66(2):115-32.

2. DeSantis CE, Siegel RL, Sauer AG, Miller KD, Fedewa SA, Alcaraz Kl, Jemal A. Cancer statistics for African Americans, 2016: Progress and opportunities in reducing racial disparities. CA Cancer J Clin. 2016;00(00):1-19.

3. Heist RS, Engelman JA. SnapShot: non-small cell lung cancer. Cancer Cell. 2012;21(3):448. e442.

4. National Lung Screening Trial Research Team, Aberle DR, Adams AM, et al. Reduced lung-cancer mortality with low-dose computed tomographic screening. N Engl J Med. 2011;365:395-409.

5. Hasan N, Kumar R, Kavuru MS. Lung cancer screening beyond low-dose computed tomography: the role of novel biomarkers. Lung. 2014;192(5):639-48

6. Bartel DP. MicroRNAs:genomics, biogenesis, mechanism, and function. Cell. 2004:116:281-97.

7. Wightman B, Ha I, Ruvkun G. Posttranscriptional regulation of the heterochronic gene lin-14 by lin-4 mediates temporal pattern formation in C. elegans. Cell. 1993;75(5):855-62.
8. Lee RC, Feinbaum RL, Ambros V. The C. elegans heterochronic gene lin-4 encodes small RNAs with antisense complementarity to lin-14. Cell. 1993;75(5):843-54

9. Wang ZX, Bian HB, Wang JR, Cheng ZX, Wang KM, De W. Prognostic significance of serum miRNA-21 expression in human non-small cell lung cancer. J Surg Oncol. 2011;104:847-51.

10. Larzabal L, de Aberasturi A, Redrado M, Rueda P, Rodriguez MJ, Bodegas ME, Montuenga LM, Calvo A. TMPRSS4 regulates levels of integrin a5 in NSCLC through miR-205 activity to promote metastasis. Br J Cancer. 2014; 110:764-74.

11. Foss KM, Sima C, Ugolini D, Neri M, Allen KE, Weiss GJ. MiR-1254 and miR-574-5p: Serum-based microRNA biomarkers for early-stage non-small cell lung cancer. J Thorac Oncol. 2011;6:482-8.

12. Kanitz A, Imig J, Dziunycz PJ, Primorac A, Galgano A, Hofbauer GF, Gerber AP, Detmar M. The expression levels of microRNA-361-5p and its target VEGFA are inversely correlated in human cutaneous squamous cell carcinoma. PLoS One. 2012;7(11):e49568.

13. Dal Monte M, Landi D, Martini D, Bagnoli P. Antiangiogenic role of miR-361 in human umbilical vein endothelial cells: functional interaction with the peptide somatostatin. Naunyn Schmiedebergs Arch Pharmacol. 2013:386(1):15-27.

14. Liu D, Tao T, Xu B, Chen S, Liu C, Zhang L, Lu K, Huang Y, Jiang L, Zhang X, Huang $X$, Zhang L, Han C, Chen M. MiR-361-5p acts as a tumor suppressor in prostate cancer by targeting signal transducer and activator of transcription-6(STAT6). Biochem Biophys Res Commun. 2014;445(1):151-6.

15. Ma F, Song H, Guo B, Zhang Y, Zheng Y, Lin C, Wu Y, Guan G, Sha R, Zhou Q, Wang D, Zhou X, Li J, Qiu X. MiR-361-5p inhibits colorectal and gastric cancer growth and metastasis by targeting staphylococcal nuclease domain containing-1. Oncotarget. 2015;6(19):17404-16.

16. Sun JJ, Chen GY, Xie ZT. MicroRNA-361-5p inhibits cancer cell growth by targeting CXCR6 in hepatocellular carcinoma. Cell Physiol Biochem. 2016; 38(2):777-85.

17. Roth C, Stückrath I, Pantel K, Izbicki JR, Tachezy M, Schwarzenbach H. Low levels of cell-free circulating miR-361-3p and miR-625* as blood-based markers for discriminating malignant from benign lung tumors. PLoS One. 2012;7(6):e38248.

18. Chua SJ. SH2B1-the adaptor protein that could. Endocrinology. 2010;151(9):4100-2.

19. Rider L, Tao J, Snyder S, Brinley B, Lu J, Diakonova M. Adapter protein $\mathrm{SH} 2 \mathrm{~B} 1$ beta cross-links actin filaments and regulates actin cytoskeleton. Mol Endocrinol. 2009;23(7):1065-76.

20. Diakonova M, Gunter DR, Herrington J, Carter-Su C. SH2-Bbeta is a Rac-binding protein that regulates cell motility. J Biol Chem. 2002;277(1):10669-77.

21. Macfarlane LA, Murphy PR. MicroRNA: biogenesis, function and role in cancer. Curr Genomics. 2010;11(7):537-61.

22. Zhang JG, Wang JJ, Zhao F, Liu Q, Jiang K, Yang GH. MicroRNA-21(miR-21) represses tumor suppressor PTEN and promotes growth and invasion in non-small cell lung cancer (NSCLC). Clin Chim Acta. 2010:411:846-52.

23. Romano G, Acunzo M, Garofalo M, Di Leva G, Cascione L, Zanca C, Bolon B, Condorelli G, Croce CM. MiR 494 is regulated by ERK1/2 and modulates TRAIL induced apoptosis in non small cell lung cancer through BIM down regulation. Proc Natl Acad Sci U S A. 2012;109:16570-5.

24. Guan P, Yin Z, Li X, Wu W, Zhou B. Meta analysis of human lung cancer microRNA expression profiling studies comparing cancer tissues with normal tissues. J Exp Clin Cancer Res. 2012;31:54.

25. Wang Q, Wang S, Wang H, Li P, Ma Z. MicroRNAs:Novel biomarkers for lung cancer diagnosis, prediction and treatment. Exp Biol Med. 2012;237:227-35.

26. Rui L, Mathews LS, Hotta K, Gustafson TA, Carter-Su C. Identification of SH2-B 3 as a substrate of the tyrosine kinase JAK2 involved in growth hormone signaling. Mol Cell Biol. 1997;17:6633-44.

27. Cross MJ, Lu L, Magnusson P, Nyqvist D, Holmqvist K, Welsh M, ClaessonWelsh L. The Shb adaptor protein binds to tyrosine 766 in the FGFR-1 and regulates the Ras/MEK/MAPK pathway via FRS2 phosphorylation in endothelial cells. Mol Biol Cell. 2002;13:2881-93.

28. Kotani K, Wilden P, Pillay TS. SH2-B is an insulin-receptor adapter protein and substrate that interacts with the activation loop of the insulin-receptor kinase. Biochem J. 1998:335:103-9.

29. Duan C, Li M, Rui L. SH2-B promotes insulin receptor substrate 1 (IRS1)- and IRS2-mediated activation of the phosphatidylinositol 3-kinase pathway in response to leptin. J Biol Chem. 2004;279(42):43684-91. 
30. Bosco EE, Mulloy JC, Zheng Y. Rac1 GTPase: a "Rac" of all trades. Cell Mol Life Sci. 2009;66:370-4.

31. Vega FM, Ridley AJ. Rho GTPases in cancer cell biology. FEBS Lett. 2008:584:2093-101.

32. Chen QY, Xu LQ, Jiao DM, Yao QH, Wang YY, Hu HZ, Wu YQ, Song J, Yan J, Wu LJ. Silencing of Rac1 modifies lung cancer cell migration, invasion and actin cytoskeleton rearrangements and enhances chemosensitivity to antitumor drugs. Int J Mol Med. 2011;28:769-76.

33. Yuan K, Qian C, Zheng R. Prognostic significance of immunohistochemical Rac1 expression in survival in early operable non-small cell lung cancer. Med Sci Monit. 2009;15:313-9.

34. Schwarz J, Proff J, Hävemeier A, Ladwein M, Rottner K, Barlag B, Pich A, Tatge H, Just I, Gerhard R. Serine-71 phosphorylation of Rac1 modulates downstream signaling. PLoS One. 2012;7(9):e44358.

35. Zheng H, Takahashi H, Murai Y, Cui Z, Nomoto K, Niwa H. Expressions of MMP-2, MMP-9 and VEGF are closely linked to growth, invasion, metastasis and angiogenesis of gastric carcinoma. Anticancer Res. 2006;26:3579-83.

36. Tsai CY, Wang CS, Tsai MM, Chi HC, Cheng WL, Tseng YH, et al. Interleukin32 increases human gastric cancer cell invasion associated with tumor progression and metastasis. Clin Cancer Res. 2014;20:2276-88.

37. Fagan-Solis KD, Schneider SS, Pentecost BT, Bentley BA, Otis CN, Gierthy JF, et al. The RhoA pathway mediates MMP-2 and MMP-9-independent invasive behavior in a triple-negative breast cancer cell line. J Cell Biochem. 2013;114:1385-94.

38. Matteo Parri PC. Rac and Rho GTPases in cancer cell motility control. Cell Commun Signal. 2010;8:23.

39. Lim LP, Lau NC, Garrett-Engele P, Grimson A, Schelter JM, Castle J, et al. Microarray analysis shows that some microRNAs downregulate large numbers of target mRNAs. Nature. 2005;433:769-73.

40. Garci'a-Echeverri'a C, Zimmermann J, Evans DB, Martiny-Baron G, Pearson MA, Gao J, Fabbro D, Ruetz S, Marti A, Brueggen J, et al. In vivo antitumor activity of NVP-AEW541-A novel, potent,and selective inhibitor of the IGFIR kinase. Cancer Cell. 2004;5:231-9.

41. Sun $\mathrm{H}, \mathrm{Ma}$ X. alpha5-nAChR modulates nicotine-induced cell migration and invasion in A549 lung cancer cells. Exp Toxicol Pathol. 2015;67(9):477-82.

42. Zhang $\mathrm{H}$, Duan $\mathrm{C}$, Zhang $\mathrm{H}$, Cheng $\mathrm{Y}$, Zhang $\mathrm{C}$. Expression of SH2B1 adaptor protein in oesophageal cancer and its clinical significance. Zhong Nan Da Xue Xue Bao Yi Xue Ban. 2013;38(2):125-31.

43. Liu S, Qi L, Han W, Wan X, Jiang S, Li Y, Xie Y, Liu L, Zeng F, Liu Z, Zu X. Overexpression of Wip1 is associated with biologic behavior in human clear cell renal cell carcinoma. PLoS One. 2014;9(10):e110218.

44. Liu S, Qi L, Yu Q, Song Y, Han W, Zu X, Jiang S, Yuan J, Zeng F, Xie Y. Survivin and HLA-I expression predicts survival of patients with clear cell renal cell carcinoma. Tumour Biol. 2014:35(8):8281-8.

\section{Submit your next manuscript to BioMed Central and we will help you at every step:}

- We accept pre-submission inquiries

- Our selector tool helps you to find the most relevant journal

- We provide round the clock customer support

- Convenient online submission

- Thorough peer review

- Inclusion in PubMed and all major indexing services

- Maximum visibility for your research

Submit your manuscript at www.biomedcentral.com/submit
C Biomed Central 